\title{
Tecnura
}

\section{Inconvenientes del uso de promedios de parámetros fisicoquímicos no conservativos, ejemplos de caso lagunas costeras mexicanas}

\section{Disadvantages of the use of average of non-conservative physicochemical parameters, case examples mexican coastal lagoons}

\author{
Guadalupe de la Lanza Espino ${ }^{\circledR}$, Salvador Hernández Pulido ${ }^{\circledR}$, \\ Francisco José Gutiérrez Mendieta ${ }^{3}$
}

Fecha de recepción: 30 de Noviembre de 2019

Fecha de aceptación: 6 de Mayo de 2020

Cómo citar: De la Lanza-Espino., G. Hernández - Pulido., S. y Gutiérrez-Mendieta., F.J. (2020). Inconvenientes del uso de promedios de parámetros fisicoquímicos no conservativos, ejemplos de caso lagunas costeras mexicanas. Tecnura, 24(65) 85-101. DOI: 10.14483/22487638.15973

\section{Resumen}

Contexto: La amplia variación en los parámetros fisicoquímicos y biológicos costeros es resultado de factores locales naturales: clima, geomorfología, influencia marina, descargas fluviales, como los antropogénicos; esto desencadena alteraciones que han dado lugar al uso de promedios que no reflejan la realidad acuática. Por esto, el presente estudio analiza la justificación teórica, los parámetros conservativos, no conservativos y biológicos del agua de lagunar costera, tanto del golfo de México como del Pacífico mexicano, a través de datos referidos como mínimos, máximos y promedio, y su grado certeza. Metodología: Se recabó información fisicoquímica y biológica de once lagunas costeras con diferencias ambientales extremas: cinco de la vertiente del Golfo de México y seis del Pacífico mexicano, según la disponibilidad y continuidad de la información.
Resultados: Los intervalos de los parámetros (máximo y mínimo) fueron significativamente amplios, asociados a factores climáticos estacionales (precipitación y estiaje), descargas fluviales temporales o permanentes, manejo del agua en el área terrestre adyacente, así como por la influencia mareal. Por consiguiente, emplear un promedio basado en máximos y mínimos no es recomendable. En los parámetros no conservativos hubo diferencias de variación cortas o de mayor amplitud, debido a la dinámica de circulación y época -a la anualidad e interanualidad-, por lo que no es recomendable utilizar promedios. Con base en lo anterior, se estimaron mayores variaciones en los parámetros acuáticos en las lagunas del Pacífico y mayor homogeneidad en las del golfo de México, resultado de la regularidad fluvioclimática, menor influencia antropogénica y de menor manejo costero.

1 Doctora, Investigadora Titular, Laboratorio de Hidrobiología, Instituto de Biología, Universidad Nacional Autónoma de México, México. Contacto: gdlle@unam.mx

2 Técnico Académico, Laboratorio de Hidrobiología, Instituto de Biología, Universidad Nacional Autónoma de México, México. Contacto: fshp@ib.unam.mx

3 Doctor en Ciencias Biológicas, Investigador Titular, Laboratorio de Ecosistemas Costeros, Departamento de Hidrobiología, Universidad Autónoma Metropolitana-Iztapalapa, México. Contacto: fgm@xanum.uam.mx 
Conclusiones: Para un diagnóstico con una visión integrativa de los factores fisicoquímicos y biológicos costeros, es necesario basarse en el conocimiento de las condiciones normales locales que incluyen: la dinámica física, fluvial, geomorfológica e influencias terrestres adyacentes, para diferenciarse de los impactos antropogénicos que modifican las características acuáticas; por esta razón, no es adecuado referir los resultados como mínimos, máximos y promedios, que en muchos casos el intervalo entre el primero y el último puede ser amplio, inseguro y erróneo; además de no ser repetitivos o permanentes y variar heterogéneamente, como se pudo apreciar en las lagunas elegidas del golfo de México y el Pacífico mexicano.

Palabras clave: parámetros fisicoquímicos, lagunas costeras de México.

\section{Abstrac}

Context: The wide variation in coastal physicochemical and biological parameters are the result of natural local factors: climate, geomorphology, marine influence, river discharges, resulting in wide variations and this has resulted in the use of averages that do not reflect aquatic reality Therefore, the present study analyzes the theoretical behavior of the conservative and non-conservative and biological parameters of coastal lagoons of both the Gulf of Mexico and the Mexican Pacific, through data referred to as minimum, maximum and average, and their degree of certainty.

Methodology: Physicochemical and biological information was collected from 11 coastal lagoons with extreme environmental differences: five from the Gulf of Mexico and six from the Mexican Pacific, according to the availability and continuity of the information.
Results: The intervals of the conservative and non-conservative parameters (maximum and minimum) were significantly wide, associated with seasonal climatic factors (rainfall and dry season), temporary or permanent river discharges, water management in the adjacent land area, as well as by tidal influence. Therefore, using an average based on maximum and minimum of those parameters is not recommended. In the non-conservative parameters, there were short or larger differences in variation; due to the dynamics of circulation, season, even, to the annual until the interannual, so it is not advisable to use averages. Based on the above, greater variations in aquatic parameters were estimated in the lagoons of the Pacific and greater homogeneity in those of the Gulf of Mexico, as a result of fluvioclimatic regularity, less anthropogenic influence and less coastal management.

Conclusions: For a diagnostic analysis with an integrative view of coastal physicochemical and biological factors, it is necessary to rely on knowledge of local normal conditions that include: physical dynamics, river, geomorphological dynamics and adjacent terrestrial influences, to differentiate from anthropogenic impacts, which they modify the aquatic characteristics; therefore, it is not appropriate to refer the results as minimum, maximum and average that in many cases the interval between the first and the last can be wide, with insecure and erroneous results; in addition to not being repetitive or permanent and vary heterogeneously, as could be seen in the chosen lagoons of the Gulf of Mexico and the Mexican Pacific.

Keywords: physicochemical parameters, coastal lagoons of Mexico

\section{INTRODUCCIÓN}

El intervalo de concentración de los parámetros fisicoquímicos acuáticos conservativos (temperatura, salinidad) y no conservativos (oxígeno disuelto, nutrientes nitrogenados y fosforados), así como los biológicos (clorofila y producción primaria) en costas del Pacífico y del Golfo de México, es altamente variable, y depende de factores ambientales como el clima de comportamiento anual (por época o por estación), hidrometeorológicos eventuales incluso extraordinarios, diferencias 
geomorfológicas (lagunas, estuarios, esteros, bahías y marismas) y actualmente de manera relevante antropogénicos; además sus interacciones con los cambios espaciales o temporales, de escalas de diferente magnitud, en general en la zona costera son cortas (Fichez et al., 2019). Lo anterior debe de tomarse en cuenta en la interpretación de los intervalos de concentración de componentes acuáticos, la amplia variación de los no conservativos que ha dado lugar al empleo de los promedios como artificio para intentar explicar su condición fisicoquímica o estado trófico y, en casos particulares, su variación espacio-temporal y su influencia en la distribución de especies. Adicionalmente, los promedios se han empleado en lo que se ha generalizado como calidad del agua, sin embargo, estos solamente pueden emplearse en balances de masa, sal y nutrientes (LOICZ, 1997; Smith et al., 1997) o en monitoreos irregulares de un limitado número de parámetros y sitios de muestreo; por ejemplo, los usados en las Normas Oficiales Mexicanas, en las que para interpretar los resultados de un análisis ambiental se comparan con normas extranjeras, generalmente de otras latitudes, en cuyo caso es preferible investigar para comparar las variaciones de los parámetros con lagunas cercanas o con registros anteriores del mismo ambiente, aunque esta situación tiene también sus inconvenientes porque no han sido las mismas metodologías que fueron empleadas para su determinación, las cuales tienen que ver más con el consumo o empleo del agua por el ser humano que con aspectos ecológicos. En muchas ocasiones, los estudios que involucran características taxonómicas, los especialistas determinan solo ciertos parámetros fisicoquímicos puntuales o promedio, para asociarlos en su identificación o en ciclos de vida de organismos acuáticos e incluso con condiciones de contaminación (bioindicadores). Los estudios ecológicos deben estar basados en una red de monitoreo regular, amplia y justificada; asimismo, y en particular, en aspectos biológicos que deben tomar en cuenta los ciclos diurnos, semanales, por época o por año, según sean los objetivos lo que permite estimar condiciones naturales y sus tendencias de contaminación.

El problema de emplear los promedios de los parámetros fisicoquímicos o biológicos es que los resultados obviamente no consideran los cambios ambientales a pequeña escala, como la mezcla vertical u horizontal por efectos eólicos o marales, las descargas continentales fluviales temporales $\mathrm{u}$ ocasionales, ya sea naturales o modificadas por el hombre (represamientos) que dan como resultado una distribución heterogénea o en parches de manera transitoria como en el contenido de clorofila a que en muchos casos es altamente fluctuante. Esta situación es similar en ciertos parámetros que muestran intervalos de diferente magnitud, hasta en periodos de horas, y ciertos autores estiman como intervalos permanentes, lo que requiere de un adecuado conocimiento. Por su parte, Hernández y Gómez (2014) postulan que procesos físicos a pequeña escala, como la turbulencia, la circulación local o la formación de pequeños giros (celdas de Langmuir) o filamentos, condicionan una elevada variabilidad. De la misma manera, Pirela, Troccoli y Hernández (2008) señalan que existen diferencias significativas temporales en la temperatura, velocidad del viento, salinidad, amonio, nitrito, nitrato, fosfato y clorofila A; el mismo microfitoplancton muestra diferencias indicadoras temporales en abundancia total, por grupos y riqueza. Según Mann y Lazier (1991), los principales procesos reguladores del fitoplancton son: las surgencias costeras y las celdas de Langmuir, las cuales provocan migración vertical del plancton y por tanto se subestiman en la interpretación los resultados.

Dentro de las técnicas empleadas para determinar producción primaria neta están: la que se considera más precisa que es el $\mathrm{C}^{14}$; sin embargo, con ciertos inconvenientes en la aplicación en sistemas lagunares por la adsorción de este isotopo por las arcillas y requiere reactivos, equipo y material altamente específico que la hacen costosa. La más frecuentemente empleada es la medición de la producción primaria a través de los cambios 
en la concentración de oxígeno, debido a la fotosíntesis y respiración en botellas claras y obscuras, respectivamente. Esta técnica es de baja sensibilidad y reproducibilidad, debido a que comúnmente se obtienen resultados negativos, en virtud de que se registra una mayor producción de oxígeno en la botella obscura que en la clara, lo cual puede deberse a la fotorrespiración o la presencia de cianobacterias con actividad fotosintética oxigénica, que es la modalidad de fotosíntesis en la que el agua es el donante primario de electrones y que, por tanto, libera oxígeno $\left(\mathrm{O}_{2}\right)$ en la obscuridad (Florencio et al., 2019), todo lo anterior induce a malas interpretaciones.

Así mismo, los heterótrofos presentes en las botellas claras (que frecuentemente tienen una alta carga orgánica) requieren oxígeno para degradarla reduciendo las concentraciones de este gas, dando como resultados producciones primarias bajas o frecuentemente negativas. Por su parte Sosa, MiIlán y Santamaría (1997) concluyen que, debido a su abundancia, es importante considerar a las bacterias en estudios encaminados a estimar la productividad primaria en cuerpos costeros, ya que afectan el resultado del método de oxígeno, por la utilización de este gas por parte de las bacterias cuando hay suficiente sustrato orgánico dentro de las botellas. Con base en lo anterior, fue difícil considerar estos parámetros para incluirlos en la evaluación de la producción primaria.

Hay que destacar la importancia de la diversidad de metodologías empleadas, según el parámetro; por ejemplo, en el caso de parámetros conservativos (temperatura y salinidad) puede ser recomendable el empleo de un multisensor, sin embargo, este puede tener una limitada sensibilidad para algunos no conservativos (oxígeno y nutrientes); adicionalmente se deben considerar errores de laboratorio, muchas veces no reportados.

Cuando se trate de evaluar tendencias de variación de parámetros en el agua que alimentan a las lagunas costeras a través de cuencas fluviales, estas pueden presentar modificaciones en su volumen y su composición fisicoquímica de forma natural e incluso por su represamiento; por otra parte, actividades antropogénicas ubicadas en las márgenes de los ríos descargan directamente aguas residuales a las cuencas, ya sea fluvial o lagunar, y que por efectos de la circulación se pueden presentar gradientes altamente heterogéneos. Por lo anterior, se debe insistir que en muchas ocasiones será necesario que los registros de los parámetros sean bajo una red de estaciones de muestreo claramente justificados, con una frecuencia que permita representar los intervalos de variación, asociándolos con aspectos geomorfológicos, hidrológicos fluviales y de relevancia climática, incluyendo los sociales, económicos y antropogénicos lo cual permitirá discriminar los cambios naturales de los impactos generados por la contaminación.

A partir de lo anterior, el objetivo del presente trabajo fue analizar la representatividad de los resultados expresados a través del mínimo, el máximo y promedio, tomando en cuenta que no son resultados permanentes ni repetibles y continuarán con su variación temporal a escalas diferentes, según el parámetro y las diversas influencias internas y externas. Para justificar lo anterior, se realizó un análisis basado en la teoría y en la información publicada de once sistemas lagunares costeros mexicanos (seis del Pacífico y cinco del golfo de México).

\section{METODOLOGÍA}

Con el fin de enfatizar el problema del empleo de los promedios de variables que presentan grandes diferencias entre el máximo y el mínimo, se recabó información fisicoquímica de once sistemas costeros con diferencias geológicas, climáticas, y fenómenos eventuales, incluso como consecuencia de las actividades humanas (presas, agricultura, descargas residuales antropogénicas). Las lagunas costeras que se analizaron fueron cinco de la vertiente del golfo de México y seis del Pacífico mexicano (figura 1), según la disponibilidad y continuidad de la información. 
Los parámetros conservativos analizados fueron temperatura y salinidad; los no conservativos fueron: oxígeno disuelto incluyendo su saturación, amonio, nitratos, nitritos, nitrógeno total, ortofosfatos, fósforo total y los biológicos: clorofila a y el índice de fertilidad relativa basado en el contenido de dicho pigmento (Ryther y Yentsch 1957), índice considerado en el presente análisis como equivalente a la producción orgánica bruta por día, aunque diversos autores no consideran que exista una correlación; sin embargo, Sosa, Gaxiola, Olivos e Iñiguez (2013), y Arreola (2003) muestran una correlación importante entre ambos términos; por ejemplo, en la laguna de Cuyutlán, México y laguna El Salitre, Colombia.

Para el análisis de todos los parámetros individuales se generaron las tablas $1 \mathrm{a}$ y $1 \mathrm{~b}$, con el fin de analizar la problemática de referir los resultados en el formato de sus intervalos (máximo, mínimo y promedio) y examinar las diferencias por cada vertiente (Pacífico y golfo de México).

\section{RESULTADOS}

Dentro de los parámetros conservativos en las lagunas de ambas vertientes, la temperatura ha sido el factor que ha mostrado intervalos relativamente constantes, que están determinados por el patrón climático anual, así como la ubicación de cada laguna costera de latitudes tropicales, presentando cambios menos amplios que la de los otros parámetros (tablas 1a y 1b). Los intervalos de salinidad (máximo y el mínimo) fueron significativamente amplios para las lagunas de ambas vertientes (tablas 1a y 1b) y están asociadas a factores climáticos estacionales (precipitación y estiaje), además de las generadas por las descargas fluviales ya sean temporales o permanentes, por escurrimientos en

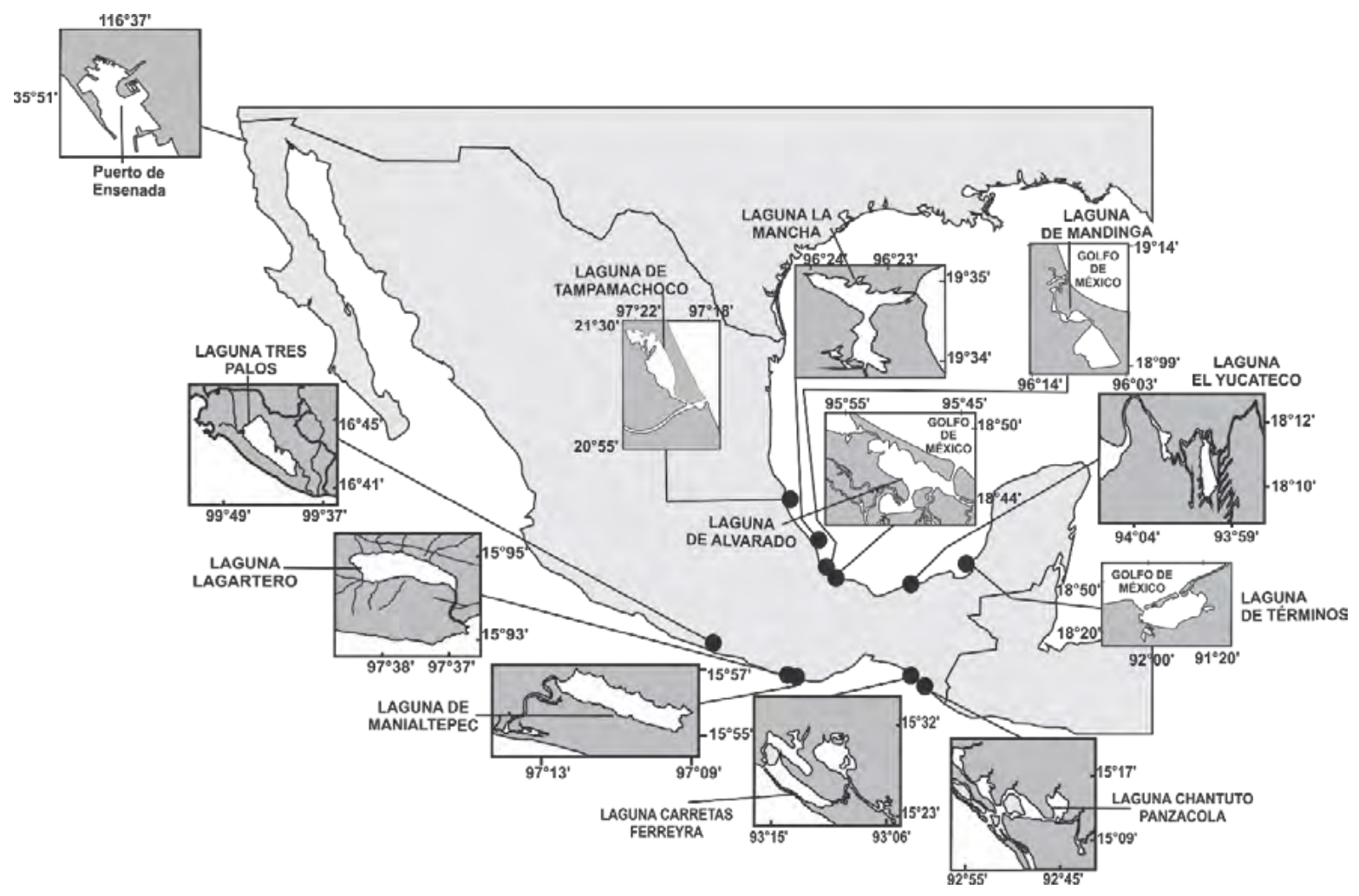

Figura 1. Localización de las lagunas costeras que se analizaron en el golfo de México y Pacífico mexicano Fuente: elaboración propia. 
sus márgenes, manejo del agua en el área terrestre adyacente (Bueno, Marceleño, Nájera y De Haro, 2019), así como por la influencia mareal, entre otros. Por tanto, emplear un promedio basado en máximos y mínimos de este factor que está involucrado en varias funciones biológicas, como en procesos osmóticos, metabólicos, así como en la distribución espacial y sucesional de los organismos, además de la desaparición de especies en ciertas zonas, y en diferentes etapas de ciclos de vida particularmente en fauna diádroma (Willmer, Stone y Johnston, 2005), no es recomendable aun siendo un factor conservativo.

En el caso de los no conservativos (considerados reactivos química y biológicamente), las diferencias en escalas de variación van desde las dimensiones puntuales (en parches), por ejemplo la fotosíntesis-respiración, y de mayor escala como diurnas, por época, anual o interanuales, resultado de influencias hidrogeológicas, cambio climático, entre otros factores ambientales; por lo que no es posible utilizar los promedios. Desde el punto de vista biológico general o puntual, la variación de estos factores no conservativos afecta no solo respuestas metabólicas, la tasa respiratoria y sobrevivencia tanto de organismos acuáticos pelágicos como bentónicos (Willmer, Stone y Johnston, 2005).

El contenido de oxígeno disuelto en los ambientes acuáticos costeros es ampliamente variable y heterogéneo, observables por las diferencias entre el mínimo y máximo en cualquier laguna costera, por lo que considerar únicamente el promedio no es recomendable (tablas 1 a y 1 b), dado que este no da idea tanto de condiciones de hipoxia (por oxidaciones orgánicas e inorgánicas y respiración), como de aeración (incluida la saturación) resultante de la fotosíntesis, procesos que se llevan a cabo durante las horas diurnas. Adicionalmente, otros factores pueden ser relevantes a nivel puntual, razón por la cual la interpretación de sus resultados deben ser hechos considerando únicamente los periodos muestreados y no hacer extrapolaciones para definir un ciclo diurno completo o temporal.
En cuanto a lo observado en las lagunas consignadas, no se encontraron particularidades regionales de variación entre las del golfo de México y del Pacífico. En el caso del cálculo del porcentaje de saturación, dado que se basa en la solubilidad de este gas según temperatura y salinidad fundamentalmente, este parámetro es aplicable para estimar los límites de tolerancia de peces y algunos organismos bentónicos. Pérez y Rodríguez (2008) emplearon este porcentaje y calcularon el índice de calidad del agua-Fundación Nacional de Salud (ICA-NSF) y consideraron que se ajustaba, en general, a la realidad de las especies tropicales, donde el porcentaje ideal para muchos peces es mayor a $67 \%$, mientras que las concentraciones de oxígeno disuelto menores a $55 \%$ afectan adversamente la biodiversidad y la supervivencia de la comunidad biótica. Adicionalmente, concentraciones superiores a 100 \% de saturación de oxígeno disuelto pueden resultar peligrosas para la vida acuática, pues facilitan que burbujas de oxígeno bloqueen el flujo sanguíneo (Chapman, 1996). En el caso de las lagunas costeras aquí analizadas, las sobresaturaciones más conspicuas se presentaron en las lagunas tanto del golfo de México, donde osciló entre $42 \%$ hasta $92 \%$ de saturación; como en el Pacífico, desde $31 \%$ al $58 \%$, incluso del $57 \%$ a $280 \%$ como en la laguna Tres Palos, considerada de una alta contaminación. En lagunas de ambas vertientes se registraron saturaciones que pueden ser resultado de circunstancias locales, en los que la fotosíntesis haya sido extremadamente alta o muy baja, o también la presencia de descargas de aguas de desecho que agotan el oxígeno (tablas $1 \mathrm{a}$ y $1 \mathrm{~b}$ ). Por lo anterior, se ratifica que es difícil calificar a los ambientes costeros únicamente con registros promediados.

El amonio es un ion $\left(\mathrm{NH}_{4}^{+}\right)$y no un gas $\left(\mathrm{NH}_{3}\right)$ pero que frecuentemente se refiere en forma errónea en las publicaciones como amonio. Las concentraciones de este ion son muy variables en ambientes acuáticos tanto lénticos como lóticos, de aguas dulces o salobres costeras, de condiciones aireadas o hipóxicas. Es importante mencionar 
Tabla 1a. Características fisicoquímicas y biológicas (clorofila A y producción primaria) en los sistemas lagunares del Pacífico mexicano.

\begin{tabular}{|c|c|c|c|c|c|c|c|c|c|c|c|c|}
\hline & Temp. ${ }^{\circ} \mathrm{C}$ & $\begin{array}{l}\text { Sal. } \\
\text { UPS }\end{array}$ & $\begin{array}{c}\text { O. Dis. } \\
\text { mg/L }\end{array}$ & $\begin{array}{c}\text { Sat. } \\
\text { Oxi \% }\end{array}$ & $\begin{array}{l}\mathrm{NH}_{4} \\
(\mu \mathrm{M})\end{array}$ & $\begin{array}{c}\mathrm{NO}_{3}+\mathrm{NO}_{2} \\
(\mu \mathrm{M})\end{array}$ & $\begin{array}{l}\text { N Tot. } \\
(\mu \mathrm{M})\end{array}$ & $\begin{array}{l}\text { PO4 } \\
(\mu \mathrm{M})\end{array}$ & $\begin{array}{l}\text { P Tot. } \\
(\mu \mathrm{M})\end{array}$ & $\begin{array}{c}\text { Clor. a } \\
\left(\mathrm{mg} / \mathrm{m}^{3}\right)\end{array}$ & $\begin{array}{l}\text { Prod prim } \\
\left(\mathrm{gC} / \mathrm{m}^{3} / \mathrm{d}\right)\end{array}$ & Referencia \\
\hline \multicolumn{13}{|c|}{ PUERTO DE ENSENADA (2004) } \\
\hline MÍN. & 16,5 & 33,0 & 1,8 & 23,4 & 0,3 & 0,1 & 1,2 & 0,1 & 0,3 & 0,1 & 0,02 & \multirow{3}{*}{$\begin{array}{l}\text { - De la Lanza } \\
\text { - et al., } 2006\end{array}$} \\
\hline MÁX. & 22,7 & 33,7 & 6,4 & 92,8 & 11,9 & 3,1 & 26,1 & 2,9 & 8,7 & 16,5 & 2,65 & \\
\hline PROM & 18,8 & 33,3 & 4,2 & 56,8 & 3,1 & 1,3 & 12,7 & 0,9 & 2,7 & 8,1 & 1,30 & \\
\hline \multicolumn{13}{|c|}{ LAGARTER0 $(1998,1999)$} \\
\hline MÍN. & 21,0 & 1,0 & 0,7 & 8,0 & 0,1 & 0,2 & 0,9 & 0,4 & 1,0 & 0,6 & 0,10 & \multirow{3}{*}{$\begin{array}{l}\text { De la Lanza } \\
\text { - y Hernández, } \\
1999 \text { informe }\end{array}$} \\
\hline MÁX. & 33,0 & 32,0 & 6,7 & 113,6 & 5,8 & 23,9 & 33,4 & 7,5 & 15,2 & 248,0 & 39,90 & \\
\hline PROM. & 29,6 & 16,8 & 3,6 & 52,2 & 2,5 & 3,4 & 6,8 & 1,8 & 4,1 & 37,1 & 5,97 & \\
\hline \multicolumn{13}{|c|}{ LAGUNA DE TRES PALOS (2003) } \\
\hline MíN. & 29,3 & 2,2 & 4,3 & 56,6 & 0,1 & 14,3 & 21,4 & 1,3 & 3,6 & 96,1 & 15,45 & \multirow{3}{*}{$\begin{array}{l}\text { De la Lanza } \\
\text { - et al., } 2008\end{array}$} \\
\hline MÁX. & 33,0 & 3,6 & 19,9 & 280,3 & 41,4 & 50,0 & 250,0 & 27,4 & 80,6 & 155,5 & 25,01 & \\
\hline PROM. & 30,5 & 3,2 & 10,6 & 141,3 & 9,3 & 29,2 & 101,3 & 6,3 & 23,9 & 125,0 & 20,11 & \\
\hline \multicolumn{13}{|c|}{ CHANTUTO-PANZACOLA (2014) } \\
\hline MíN. & 0,2 & 17,0 & 0,9 & 9,6 & 3,0 & 6,3 & 12,3 & 16,3 & 19,0 & 0,6 & 0,09 & \multirow{7}{*}{$\begin{array}{l}\text { Gómez et al., } \\
2017\end{array}$} \\
\hline MÁX. & 35,5 & 35,5 & 6,8 & 119,3 & 134,7 & 177,8 & 289,4 & 286,7 & 571,0 & 90,1 & 14,49 & \\
\hline PROM. & 13,4 & 29,6 & 2,7 & 31,8 & 24,1 & 90,9 & 88,5 & 58,6 & 88,8 & 17,7 & 2,85 & \\
\hline \multicolumn{12}{|c|}{ CHANTUTO-PANZACOLA (2015) } & \\
\hline MIN & 14,0 & 0,6 & 0,2 & 2,0 & 3,2 & 6,3 & 9,5 & 4,4 & 54,0 & 0,1 & 0,02 & \\
\hline MAX & 37,0 & 40,0 & 17,0 & 346,9 & 134,5 & 186,5 & 321,0 & 92,4 & 199,0 & 131,4 & 21,14 & \\
\hline PROM & 28,6 & 13,6 & 5,7 & 79,7 & 92,0 & 89,9 & 181,9 & 55,6 & 117,0 & 27,0 & 4,34 & \\
\hline \multicolumn{13}{|c|}{ CHANTUTO-PANZACOLA () } \\
\hline MíN. & 25,6 & 0,0 & 0,1 & 11,0 & 0,1 & 0,0 & 0,5 & 0,1 & & 0,1 & 0,01 & \multirow{3}{*}{$\begin{array}{l}\text { Gutiérrez, } \\
\text { com. personal }\end{array}$} \\
\hline MÁX. & 35,8 & 40,0 & 12,0 & 153,0 & 28,0 & 51,0 & 54,8 & 25,9 & & 142,8 & 22,97 & \\
\hline PROM. & 30,8 & 14,8 & 3,2 & 64,0 & 4,6 & 8,1 & 12,0 & 4,7 & & 21,7 & 3,49 & \\
\hline \multicolumn{13}{|c|}{ LAGUNA MANIALTEPEC (1989) } \\
\hline MíN. & 21,0 & 3,0 & 2,6 & 30,6 & 3,7 & 3,5 & 2,5 & 0,1 & 2,9 & 0,1 & 0,02 & \multirow{3}{*}{$\begin{array}{l}\text { - Contreras y } \\
\text { - Warner, } 2004\end{array}$} \\
\hline MÁX. & 31,0 & 6,5 & 4,1 & 57,7 & 28,8 & 8,2 & 150,7 & 4,3 & 15,7 & 256,0 & 41,18 & \\
\hline PROM. & 26,0 & 4,8 & 3,4 & 43,9 & 16,3 & 5,9 & 33,7 & 2,2 & 8,7 & 39,1 & 6,29 & \\
\hline \multicolumn{13}{|c|}{ LAGUNA MANIALTEPEC } \\
\hline MíN. & 21,0 & 6,2 & 0,3 & 5,0 & 0,6 & 0,2 & 1,1 & 0,6 & 1,3 & 0,4 & 0,06 & \multirow{3}{*}{$\begin{array}{l}\text { Gutiérrez, } \\
\text { com. personal }\end{array}$} \\
\hline MÁX. & 39,5 & 77,2 & 9,7 & 222,0 & 12,5 & 10,5 & 16,7 & 13,2 & 33,8 & 256,0 & 41,18 & \\
\hline PROM. & 29,8 & 36,0 & 4,4 & 98,0 & 5,0 & 1,5 & 6,6 & 3,1 & 8,0 & 39,1 & 6,29 & \\
\hline \multicolumn{13}{|c|}{ CARRETAS PEREYRA (2010) } \\
\hline MíN. & 1,3 & 29,0 & 3,8 & 50,0 & 1,7 & 1,7 & 3,4 & 2,0 & 10,4 & 8,2 & 1,32 & \multirow{3}{*}{$\begin{array}{l}\text { Contreras, } \\
2010\end{array}$} \\
\hline MÁX. & 34,6 & 33,2 & 6,6 & 111,9 & 24,9 & 4,1 & 27,2 & 30,7 & 33,1 & 55,4 & 8,91 & \\
\hline PROM. & 18,0 & 31,1 & 5,2 & 77,6 & 13,3 & 2,9 & 15,3 & 16,4 & 21,8 & 31,8 & 5,12 & \\
\hline \multicolumn{13}{|c|}{ CARRETAS PEREYRA } \\
\hline MÍN. & 27,3 & 0,0 & 0,8 & 18,0 & 0,2 & 0,2 & 1,0 & 0,1 & & 0,2 & 0,03 & \multirow{3}{*}{$\begin{array}{l}\text { Gutiérrez, } \\
\text { com. personal }\end{array}$} \\
\hline MÁX. & 36,1 & 38,7 & 11,2 & 201 & 29,9 & 66,8 & 68,2 & 39,1 & & 26,5 & 4,26 & \\
\hline PROM. & 31,9 & 16,2 & 4,1 & 83 & 4,2 & 9,3 & 13,1 & 7,3 & & 6,7 & 1,07 & \\
\hline
\end{tabular}

Fuente: elaboración propia. 
Tabla 1b. Características fisicoquímicas y biológicas (clorofila a y producción primaria) en los sistemas lagunares en el golfo de México.

\begin{tabular}{|c|c|c|c|c|c|c|c|c|c|c|c|c|}
\hline & $\underset{{ }^{\circ} \mathrm{C}}{\text { Temp. }}$ & $\begin{array}{l}\text { Sal. } \\
\text { UPS }\end{array}$ & $\begin{array}{c}\text { O. Dis. } \\
\mathrm{mg} / \mathrm{L}\end{array}$ & $\begin{array}{c}\text { Sat. Oxi } \\
\%\end{array}$ & $\begin{array}{l}\mathrm{NH}_{4} \\
(\mu \mathrm{M})\end{array}$ & $\begin{array}{c}\mathrm{NO}_{3}+\mathrm{NO}_{2} \\
(\mu \mathrm{M})\end{array}$ & $\begin{array}{l}\text { N Tot. } \\
(\mu \mathrm{M})\end{array}$ & $\begin{array}{l}\mathrm{PO} 4 \\
(\mu \mathrm{M})\end{array}$ & $\begin{array}{l}\text { P Tot. } \\
(\mu \mathrm{M})\end{array}$ & $\begin{array}{c}\text { Clor. a } \\
\left(\mathrm{mg} / \mathrm{m}^{3}\right)\end{array}$ & $\begin{array}{l}\text { Prod prim } \\
\left(\mathrm{gC} / \mathrm{m}^{3} / \mathrm{d}\right)\end{array}$ & \\
\hline \multicolumn{13}{|c|}{ LAGUNA DE TAMPAMACHOCO (2009) } \\
\hline MÍN. & 25,9 & 16,8 & 3,4 & 51,1 & 0,7 & 0,1 & 5,0 & 0,3 & 2,6 & 1,6 & 0,3 & \multirow{3}{*}{$\begin{array}{l}\text { De la Lanza, } \\
\text { Hernández y } \\
\text { Carbajal, } 2014\end{array}$} \\
\hline MÁX. & 29,8 & 37,4 & 10,5 & 181,0 & 15,7 & 1,6 & 37,9 & 3,6 & 7,7 & 13,6 & 2,2 & \\
\hline PROM. & 27,3 & 29,9 & 7,0 & 106,1 & 8,6 & 0,3 & 18,4 & 1,5 & 4,2 & 5,3 & 0,9 & \\
\hline \multicolumn{13}{|c|}{ LAGUNA DE TAMPAMACHOCO (2010) } \\
\hline MÍN. & 25,5 & 3,4 & 3,6 & 53,6 & 19,3 & 0,8 & 30,0 & 0,7 & 3,6 & 18,2 & \multicolumn{2}{|l|}{2,9} \\
\hline MÁX. & 26,6 & 27,4 & 7,6 & 100,0 & 35,0 & 2,2 & 40,7 & 6,8 & 28,1 & 31,4 & \multicolumn{2}{|l|}{5,1} \\
\hline PROM. & 26,2 & 16,1 & 5,6 & 75,2 & 23,7 & 1,5 & 34,4 & 2,5 & 13,7 & 21,1 & \multicolumn{2}{|l|}{3,4} \\
\hline \multicolumn{13}{|c|}{ LAGUNA DE TAMPAMACHOCO (2012) } \\
\hline MÍN. & 27,7 & 1,5 & 6,8 & 97,0 & 20,7 & 1,0 & 24,3 & 1,9 & 7,1 & 2,4 & \multicolumn{2}{|l|}{0,4} \\
\hline MÁX. & 29,3 & 26,5 & 13,0 & 174,0 & 30,0 & 6,5 & 70,7 & 88,7 & 123,9 & 15,9 & \multicolumn{2}{|l|}{2,6} \\
\hline PROM. & 28,6 & 15,9 & 8,4 & 115,8 & 24,7 & 2,9 & 47,9 & 30,5 & 56,1 & 8,2 & \multicolumn{2}{|l|}{1,3} \\
\hline \multicolumn{13}{|c|}{ LAGUNA LA MANCHA (2012) } \\
\hline MíN. & 24,7 & 21,5 & 5,5 & 84,3 & ND & 0,1 & 5,1 & 5,5 & 12,9 & 3,0 & 0,5 & \multirow{3}{*}{$\begin{array}{l}\text { Contreras, Ri- } \\
\text { vera y Segura, } \\
2005\end{array}$} \\
\hline MÁX. & 26,9 & 34,1 & 9,5 & 125,1 & 1,4 & 0,2 & 15,3 & 14,5 & 29,0 & 11,4 & 1,8 & \\
\hline PROM. & 25,6 & 28,5 & 7,6 & 108,7 & 0,4 & 0,1 & 10,2 & 11,3 & 23,2 & 7,2 & 1,2 & \\
\hline \multicolumn{13}{|c|}{ LAGUNA DE MANDINGA (2016) } \\
\hline MíN. & 29,1 & 8,6 & 3,2 & 43,7 & 6,4 & 0,1 & 21,4 & 1,3 & 8,1 & 2,9 & 0,5 & \multirow{3}{*}{$\begin{array}{l}\text { De la Lanza } \\
\text { y Hernández } \\
2018\end{array}$} \\
\hline MÁX. & 31,1 & 16,0 & 7,9 & 111,3 & 12,9 & 1,3 & 53,6 & 34,8 & 37,4 & 56,5 & 9,1 & \\
\hline PROM. & 30,3 & 11,7 & 5,7 & 80,9 & 8,9 & 0,5 & 32,6 & 11,2 & 16,2 & 22,8 & 3,7 & \\
\hline \multicolumn{13}{|c|}{ LAGUNA DE MANDINGA (2018) } \\
\hline MíN. & 24,9 & 27,4 & 6,8 & 101,5 & 9,3 & 0,5 & 13,6 & 3,2 & 10,0 & 8,2 & \multicolumn{2}{|l|}{1,3} \\
\hline MÁX. & 27,1 & 31,8 & 8,0 & 119,4 & 13,6 & 4,3 & 58,6 & 6,1 & 23,9 & 26,5 & \multicolumn{2}{|l|}{4,3} \\
\hline PROM. & 25,8 & 28,9 & 7,2 & 108,7 & 11,7 & 1,6 & 34,2 & 4,4 & 14,4 & 13,9 & \multicolumn{2}{|l|}{2,2} \\
\hline LAGUN & DE ALV & ARAD & $(2015)$ & & & & & & & & & \\
\hline MíN. & 25,1 & 0,2 & 3,2 & 42,6 & 15,0 & 0,1 & 35,7 & 0,3 & 1,3 & 0,6 & 0,1 & De la Lanza \\
\hline MÁX. & 31,0 & 9,6 & 9,5 & 92,3 & 24,2 & 4,6 & 314,3 & 14,2 & 50,3 & 48,8 & 7,9 & y Hernández, \\
\hline PROM. & 27,8 & 4,6 & 6,0 & 72,0 & 18,9 & 1,4 & 107,7 & 6,2 & 24,1 & 15,2 & 2,4 & 2017 \\
\hline LAGUN & DE ALV & ARAD & $(2016)$ & & & & & & & & & \\
\hline MÍN. & 27,0 & 1,8 & 6,4 & 84,7 & 14,3 & 0,1 & 35,7 & 1,9 & 22,3 & 6,5 & 1,0 & \\
\hline MÁX. & 27,5 & 5,9 & 8,3 & 106,1 & 19,3 & 0,9 & 114,3 & 6,8 & 45,5 & 11,8 & 1,9 & \\
\hline PROM. & 27,2 & 4,0 & 7,2 & 94,8 & 17,3 & 0,5 & 74,4 & 5,3 & 43,1 & 8,5 & 1,4 & \\
\hline LAGUN & EL YUC & ATECO & $(2008)$ & & & & & & & & & \\
\hline MíN. & 12,7 & 26,0 & 1,6 & 5,9 & 4,3 & 0,1 & 32,1 & 1,2 & 6,8 & 1,8 & 0,3 & \\
\hline MÁX. & 26,3 & 28,8 & 5,5 & 93,6 & 21,4 & 1,4 & 82,1 & 11,9 & 35,2 & 27,1 & 4,4 & 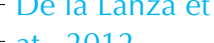 \\
\hline PROM. & 15,0 & 27,1 & 3,7 & 53,1 & 13,8 & 0,2 & 49,1 & 3,5 & 17,9 & 14,2 & 2,3 & \\
\hline LAGUN & EL YUC & ATECC & (2009) & & & & & & & & & \\
\hline MÍN. & 27,3 & 23,3 & 0,2 & 2,1 & ND & 0,1 & 9,3 & 0,3 & 3,2 & 10,0 & 1,6 & \\
\hline MÁX. & 30,2 & 33,0 & 8,5 & 122,1 & ND & 0,8 & 38,6 & 5,2 & 20,0 & 28,8 & 4,6 & \\
\hline PROM. & 28,8 & 27,8 & 5,4 & 80,2 & ND & 0,4 & 29,1 & 2,7 & 7,3 & 17,1 & 2,8 & \\
\hline LAGUN & TÉRMIN & $\operatorname{OOS}(1$ & & & & & & & & & & \\
\hline MÍN. & 24,0 & 5,0 & 4,2 & 52,5 & 0,1 & 0,2 & & 0,1 & & 2,9 & 0,5 & $\begin{array}{l}\text { De la Lanza y } \\
\text { Lozano, } 1999\end{array}$ \\
\hline MÁX. & 33,0 & 38,0 & 13,8 & 237,9 & 1,5 & 2,1 & & 7,5 & & 20,0 & 3,2 & \\
\hline PROM. & 28,0 & 21,8 & 7,2 & 104,3 & 0,5 & 0,5 & & 0,9 & & 8,2 & 1,3 & \\
\hline LAGUN & TÉRMIN & $\operatorname{lOS}(2$ & 17) & & & & & & & & & \\
\hline MÍN. & 23,4 & 4,0 & 3,0 & 32,6 & 0,02 & 0,02 & 0,04 & 0,5 & & 2,12 & 0,3 & \\
\hline MÁX. & 33,0 & 36,0 & 10,9 & 265,8 & 2,7 & 2,6 & 21,5 & 9,6 & & 71,86 & 11,6 & utiérrez, \\
\hline PROM. & 29,3 & 24,1 & 6,2 & 77,50 & 0,2 & 0,2 & 3,8 & 3,70 & & 21,97 & 3,5 & \\
\hline
\end{tabular}

Fuente: elaboración propia. 
que las variaciones de concentración no solamente pueden ser resultado de procesos que se lleven a cabo al interior de cada ambiente, cuyos factores resultan de reacciones químicas aisladas, lo que hace difícil la interpretación cuando no se tiene experiencia. Los resultados de este nutriente tienen un amplio grado de incertidumbre, no solamente por las diferentes técnicas empleadas sino por las diferencias en el manejo del personal quien las ejecuta y más aún por la falta de conocimiento adecuado para una acertada interpretación. Así mismo, existen diferentes unidades empleadas en su cuantificación y que obviamente no son comparables con las Normas Oficiales de México. En muchos casos, los intervalos entre el mínimo y el máximo se desvirtúan empleando el valor promedio, el cual no da idea clara del nivel trófico real o del grado contaminación de cualquier ecosistema acuático, y generalmente se extrapola a todo un cuerpo acuático; adicionalmente hay que considerar que este es un nutriente no conservativo. En consecuencia, es difícil recomendar el promedio, el cual solamente representa una fracción de tiempo puntual en un macrocosmos acuático.

Aplicando todo lo anterior a las lagunas costeras tanto del golfo de México como del Pacífico aquí analizadas, se puede establecer que en algunos casos sus intervalos de concentraciones han sido considerados normales, cuando se comparan con información preliminar del siglo pasado, época en donde no existían mayores descargas de aguas residuales o la influencia de la actividad agrícola marcada con uso de fertilizantes. En el caso de la laguna Chantuto Panzacola en 1993 se reportaron niveles de $\mathrm{NH}_{4}, \mathrm{NO}_{2}+\mathrm{NO}_{3}$ y $\mathrm{NT}$ (nitratos+nitritos $y$ nitrógeno total) considerados como normales (11,0; 13,$8 ; 15,5 \mu \mathrm{M}$, respectivamente); si estos valores se compararan con lo registrado 24 años después, se aprecia un incremento significativo en sus concentraciones $(92,0 ; 89,9 ; 181,9 \mu \mathrm{M}$, respectivamente). La laguna de Alvarado también ha registrado un incremento notorio: en 1985, del $\mathrm{NH}_{4}$ se cuantificaron contenidos de $0,1-7,1 \mu \mathrm{M}$, y entre $0,3-172 \mu \mathrm{M}$ de $\mathrm{NO}_{2}+\mathrm{NO}_{3}$, comparado con lo determinado veinte años después (2015), cuando se registraron 15-24,2, 0,1-4,6, 35,7-314,3 $\mu \mathrm{M}$, respectivamente.

El empleo de promedios de nutrientes se puede justificar cuando se intenta dar una idea general del incremento registrado en una laguna en un cierto periodo de tiempo sin precisar la fuente; pero algunos autores hasta elaboran gradientes de concentración con base en isolíneas sin considerar la distribución puntual, explicada previamente. En la laguna Chantuto Panzacola (Chiapas) se determinó entre 2015-2014 un incremento tanto en el valor máximo como también en el promedio de $\mathrm{NH}_{4}, \mathrm{NO}_{2}+\mathrm{NO}_{3}$ y $\mathrm{NT}$, cuyo aumento fue atribuido a una alta contaminación (tablas 1a y 1b). En 2015, en la laguna de Alvarado (golfo de México) se cuantificaron contenidos de $\mathrm{NO}_{2}+\mathrm{NO}_{3}$ de 4,6 $\mu \mathrm{M}$ considerados normales, pero con una concentración de NT elevada de $314 \mu \mathrm{M}$. En ambos casos los incrementos fueron justificados por las descargas fluviales-poblacionales y de mayor densidad agrícola, consecuentemente considerados de un nivel de contaminación de origen antropogénico, cuando en el siglo pasado (1985) las concentraciones no mostraban este impacto (NT 0,1-179,0 $\mu \mathrm{M})$, contenidos que fueron resultado de la distribución local geomorfológica o con una influencia ambiental externa normal. Al respecto, las concentraciones de nitrógeno total incluyen tanto las formas orgánicas como las inorgánicas, y se supone que en condiciones ideales la suma de $\mathrm{NH}_{4}$ más $\mathrm{NO}_{2}+\mathrm{NO}_{3}$ y la diferencia con respecto al NT correspondería a la fracción orgánica pero frecuentemente no es el caso, en consecuencia, pueden ser errores de técnica analítica o del cálculo del promedio. El incremento del NT ha sido sustancial; en la laguna de Alvarado donde Contreras, Castañeda, Torres y Gutiérrez (1996) determinaron 4,9-25 uM (15 uM prom.); veinte años después (2015) se cuantificaron entre 36 y $314 \mu \mathrm{M}$ (mínimo-máximo), es decir un incremento aproximado de 15 veces el máximo, lo que denotó una severa eutrofización; sin embargo, dada la distribución puntual de esta última concentración, pudo haber sido resultado de la ubicación 
del punto de muestreo, razón por la cual hay que tomarlo en cuenta para calificar dicho contenido, lo que resalta la importancia de no referir únicamente los promedios.

Cualquier presentación de los resultados ambientales, ya sea en forma puntual (mínimo, máximo, promedio) puede ser azarosa o errónea, ya que hay que tomar en cuenta la variación de los factores: climáticos, condiciones fisicoquímicas acuáticas y biológicas que frecuentemente condicionan una distribución en forma de parches variables en espacio tiempo y que solamente puede ser observada en forma adecuada en series de tiempo. Frecuentemente, según los objetivos de la investigación, los registros se asocian con la presencia, ausencia o sucesión de alguna especie en el medio; sin embargo, también se requeriría contar con una base de datos amplia de algún parámetro y no únicamente datos puntuales. Para determinar el grado de contaminación y su procedencia, se requeriría contar con un monitoreo y red de estaciones de estudio adecuadamente planeadas. Si se decide hacer monitoreos de la calidad del agua para medir la influencia antropogénica, sería necesario que fueran los mismos sitios de muestreo, ya que los nutrientes, al ser no conservativos, no se repetirán en el tiempo. Cabe precisar la necesidad de incluir los análisis de las mismas variables químicas acuáticas pero en el sedimento, dado que esta fase cumple un papel importante en la absorción y almacenamiento de excesos de nutrientes de la columna de agua (De la Lanza y Arenas 1978), pudiendo posteriormente favorecer su difusión hacia el agua, según el tipo de sedimento y las remociones naturales (por ejemplo, tipos de circulación) o generadas por las actividades humanas (por ejemplo, dragados). Estudios de este tipo son escasos y no se contemplan dentro de las Normas Oficiales Mexicanas; por lo que en la presente contribución se recomienda que se incluyan evaluaciones en el sedimento cuando hay modificaciones en las lagunas costeras, como: deforestación, apertura de canales y caminos, asentamientos humanos marginales, entre otros.
El otro nutriente relevante y considerado en ciertos ambientes como limitante en la producción primaria es el fósforo (ortofosfatos), también llamado fósforo reactivo soluble (FRS), y el fósforo total (PT), que incluye a las fracciones inorgánica y orgánicas. Los compuestos de fósforo tienen un comportamiento más geoquímico, que los compuestos nitrogenados que son más biogeoquímicos. Las concentraciones máximas de ortofosfatos aceptables como normales corresponden a los determinados en el siglo pasado, cuando en general en el medio ambiente se empleaban menores cantidades de fertilizantes. Los intervalos de variación aparentemente normales han sido definidos por distintos autores y esto ha dado lugar a concentraciones restrictivas injustificadas y poco representadas por su distribución en parches y no toman en cuenta la variabilidad local y la complejidad de su ciclo. Sin embargo, actualmente el incremento del PO4 en ambientes lagunares es notorio, dando como resultado procesos de eutrofización frecuentes en los cuerpos de agua costeros; por ejemplo, en la laguna de Tampamachoco (1996) se calcularon concentraciones de 0,1-1,4 (0,6 $\mu \mathrm{M}$ prom.) en el periodo 1979-1990; en 2009 se cuantificó un intervalo $0,3-3,6$ uM (1,5 uM prom.) mientras que en 2012 los contenidos fluctuaron entre 1,9$88,7 \mu \mathrm{M}(33,5 \mu \mathrm{M}$ prom.). En la laguna de Mandinga en 1996 se tenían concentraciones entre 0,15 a 1,7 $\mu \mathrm{M}$ 1996) mientras que en 2016 se cuantificaron máximos de 38,8 (11,2 $\mu \mathrm{M}$ prom.), presentando ambas lagunas una condición de eutrofización después de treinta años. En la vertiente del Pacífico existen pocos estudios que abarquen varios periodos anuales que permitan estimar algún incremento durante cierto periodo; a pesar de esto, en 2003 se analizó en una sola ocasión la fisicoquímica de la laguna de Tres Palos y se registraron condiciones de hipoxia, concentraciones de $\mathrm{NH}_{4}$ de no detectable a $41,4 \mu \mathrm{M}, \mathrm{PO}_{4}$ con contenidos de 1,3 a 27,0 $\mu \mathrm{M}$, PT 3,6 a $80,6 \mu \mathrm{M}$, y NT 21-250 $\mu \mathrm{M}$ en una serie de sitios de muestreo que permitió clasificar a esta laguna como hipertrófica, cuyos asentamientos humanos, descargas de aguas 
residuales y actividades antropogénicas diversas, condujeron a su pleno deterioro, lo que sería recomendable continuar con las determinaciones para definir su persistencia y no fuera un estudio referido aun como promedios.

Desde el punto de vista biológico el fitoplancton presenta diversos pigmentos, principalmente la clorofila a, y sus concentraciones en las lagunas costeras son amplias y complejas, resultado de los distintos factores ambientales ya señalados anteriormente, entre ellos el efecto de la luz (calidad y cantidad incluso con variación estacional), cambios en la densidad del agua (temperatura y salinidad), geomorfología, concentraciones de nutrientes, viento y procesos de circulación que hacen que fitoplancton (evaluado como clorofila A) se distribuya en forma de parches, modificando, por tanto, el intervalo de variación que presenten, que puede ser amplio con o sin signos de contaminación, por lo que es difícil precisar los resultados a través de mínimos, máximos o promedios. Este parámetro ha sido cuantificado con mayor frecuencia, por lo que existe más información desde mediados de los años 1950, aunque en ocasiones con registros muy puntuales, por lo que existen escasas publicaciones que mantengan una continuidad de evaluación en un sitio en específico.

Para una interpretación adecuada y excluir concentraciones que aparentemente indiquen contaminación, es necesario no solo contar con una red de estaciones como lo han hecho algunos autores como Conan et al. (2017) y Fichez et al. (2019) en la laguna de Términos, sino de ser posible con una base de datos de registros por época e interanuales. Cuando se refieren resultados de clorofila A como mínimo, máximo y promedio, es difícil interpretar en qué estado trófico o de contaminación se encuentra una laguna costera. Efectuar interpretaciones es poco recomendable debido a la heterogeneidad espacial del pigmento, influenciado no solo por los factores ambientales mencionados, sino también de aquellos externos como los escurrimientos terrestres naturales (por ejemplo, ríos) o antropogénicos (urbanos o agrícolas) que estimulan el crecimiento fitoplanctónico y en consecuencia los pigmentos en general.

Con la información recabada en el presente análisis, se observaron contenidos máximos de clorofila a extremadamente altos $\left(248 \mathrm{mg} / \mathrm{m}^{3}\right)$ en una de las lagunas elegidas del Pacífico (Lagartero), mientras que en la mayoría de los casos los niveles mínimos fueron muy bajos $\left(0,1 \mathrm{mg} / \mathrm{m}^{3}\right)$; esto ha dado lugar a que cuando se emplean los promedios, se suavicen las grandes diferencias que existen entre los mínimos y máximos, siendo que en algunos casos los expertos los consideran dentro de una variación normal sin discriminar, por ejemplo, el nivel trófico en que se encuentra un cuerpo de agua. Para demostrar lo anterior, destacaron las lagunas del Pacífico: Lagartero, Tres Palos, Manialtepec y Chantuto Panzacola, con máximos de 248, 155, $256 \mathrm{mg} / \mathrm{m}^{3}$, respectivamente (tablas 1a) lo cual no diferenció la condición natural de la impactada con base en los máximos; en cambio, en las lagunas del golfo de México fueron menos extremosas las diferencias $\left(1,6-56 \mathrm{mg} / \mathrm{m}^{3}\right)$ y esto puede ser resultado de diversos factores, como los fluvioclimáticos menos extremosos, el aparentemente menor número de los asentamientos humanos y sus actividades económicas del área circundante (Gutiérrez y De la Lanza 2019).

El término productividad primaria se refiere al rendimiento fotosintético (por ejemplo, producción por unidad de clorofila a). Wetzel (1975) se refirió a la producción primaria como la elaboración de material orgánico nuevo en un periodo de tiempo (o incremento de biomasa) más las perdidas en ese periodo, y productividad es el promedio de la tasa instantánea en un periodo de tiempo, usualmente día o año. Parte de la confusión surge en los primeros conceptos de productividad como máximo crecimiento y desarrollo de los organismos bajo condiciones óptimas (Thienemann, 1931).

Actualmente, se utilizan indistintamente los dos conceptos; por ejemplo, la medición de productividad $\left(\mathrm{mgC} / \mathrm{m}^{3} /\right.$ día), pero cuando es referida a una columna de agua a una profundidad $X$ promediada, ha sido referida como producción 
(mgC/m²//ía), como la reportan Gaxiola et al. (1997). Esteves (1998) señala que generalmente los términos producción y productividad primaria son utilizados indistintamente en Limnología; sin embargo, debe señalarse que la gran mayoría de los trabajos existentes se refieren a la productividad y no a la producción primaria.

Hay escasos trabajos donde se estima la producción primaria a través del pigmento; por ejemplo, Beltrán (2016) la modela en un humedal a través de la concentración promedio mensual de clorofila A. Arreola (2003) observó un mismo patrón entre la clorofila y la producción primaria $(0,664$ p $<0,05)$ (figura 2a) en la laguna de las Guásimas; al igual que lo referido por Sosa et al. (2013) en la laguna Cuyutlán (figura 2b). Por lo anterior, bajo esta diversidad de conceptos y formas de referir los dos términos, es más complicado aún emplear promedios sin comprender la dinámica de los ecosistemas acuáticos en sus particularidades espaciales y temporales, a menos de generalizar como un todo aparentemente repetible, que no debe ser el caso.

La producción primaria estimada en buen número de lagunas aquí elegidas a través de la concentración de la clorofila a y con base en Ryther y
Yentsch (1957) además de Lara y Álvarez (1975), se encontraron diferencias notorias entre el mínimo y el máximo que se suavizaron en el promedio sin tomar en consideración las variaciones estacionales o por épocas. A partir de los promedios, a pesar de los inconvenientes de utilizarlos, se observó que los resultados en ambas vertientes difieren visiblemente, siendo más regulares y menores las concentraciones en el golfo de México 0,3 a $11,6 \mathrm{gC} / \mathrm{m}^{3} / \mathrm{d}$ equivalente a 12,5 a $483 \mathrm{mgC} /$ $\mathrm{m}^{3} / \mathrm{h}$, respectivamente, así como mayores y heterogéneas en el Pacífico $\left(0,02-41 \mathrm{~g} / \mathrm{m}^{3} / \mathrm{d}\right.$ equivalente a 0,8 y $1708 \mathrm{mgC}\left(\mathrm{m}^{3} / \mathrm{h}\right.$ (tablas 1 a y $\left.1 \mathrm{~b}\right)$, que pueden ser resultado de las concentraciones puntuales de la clorofila, de las variantes climáticas estacionales extremas, de las diferencias del manejo del agua (De la Lanza y Gutiérrez 2019) e incluso por el cambio en el uso del suelo adyacente con actividades agropecuarias con escorrentías hacia los cuerpos de agua. Comparativamente con otras lagunas y a pesar del empleo de otras metodologías, los presentes resultados oscilaron dentro de lo reportado por otros autores (tabla 2).

Con base en los resultados del contenido de clorofila a y del fosforo total en las lagunas costeras

Tabla 2. Producción primaria en las lagunas costeras del golfo de México* y Pacífico**

\begin{tabular}{|c|c|c|}
\hline LAGUNA & $\mathrm{mgC} / \mathrm{m}^{3} / \mathrm{h}$ & \\
\hline Tampamachoco* & $9,4-527$ & Contreras, 2010 \\
\hline Mandinga* & $1,4-391,7$ & Contreras y Warner, 2004 \\
\hline Ostión* & $2,1-133,3$ & Contreras y Warner, 2004 \\
\hline Carretas Pereyra** & $34,2-809$ & Contreras y Warner, 2004 \\
\hline Carretas Pereyra** & nd-764 & Lara et al., 2008 \\
\hline Mazatlán-Tehuantepec** & $0,15-17,1$ & Lara y Bazán, 2005 \\
\hline Estero Urías** & $0,1-666,5$ & Lara et al., 2008 \\
\hline Cuyutlán** & $50-162$ & Sosa et al., 2013 \\
\hline Bahía de Navachiste** & $140-308$ & Quiroz, 2014 \\
\hline Escobillita, Colombia & nd-339 & Montoya y Aguirre, 2010 \\
\hline El Medio, Colombia & $3,75-352,5$ & Robayo y Rodríguez, 2015 \\
\hline Bahía de Mejillones, Chile & 930,7 octubre-noviembre & Marín y Olivares, 1999 \\
\hline Bahía de Mejillones, Chile & 155,1 enero-marzo & Marín y Olivares, 1999 \\
\hline Bahía de Mochima, Venezuela & $\begin{array}{c}\text { no surgencia } 0 \text { a } 417 \mathrm{mgC} / \mathrm{m}^{3} / \mathrm{h} \\
\text { surgencia de } 76-426\end{array}$ & González, Zoppi de Roa y Montiel, 2006 \\
\hline Sauce Grande, Argentina & $104-718$ & Cony, Ferrer y Cáceres, 2016 \\
\hline
\end{tabular}

nd $=$ no detectable

Fuente: elaboración propia. 
tropicales de México y referidas a través de máximos, mínimos y su promedio comparadas con la propuesta de la Organización para la Cooperación y el Desarrollo Económico (OCDE, 1982) (tablas 3a y 3 b), los niveles tróficos señalaron que a pesar de que se registre una amplia oscilación, lo que ha predominado en las lagunas aquí analizadas del Pacífico ha sido un nivel general de hipertrofia que podría ser normal con variación espacial y temporal sin tener problemas de eutrofización, consecuencia de diferentes factores, como la ubicación y estacionalidad de las localidades de muestreo, sin que por ello pudieran considerarse contaminadas; por esta razón, es necesario no basarse en clasificaciones fisicoquímicas y tróficas de no ser las locales, como sucede incluso con lo establecido por la Pulido y Pinilla (2017) quienes calculan y clasifican la laguna El Salitre (Colombia) en forma distinta a la propia OCDE incluyendo las distintas diferencias en las unidades. Lo anterior señala que la categorización trófica debe basarse latitudinal y localmente con una base de datos amplia.

Tabla 3a. Valores límite para la clasificación trófica de la OCDE $1982(\mu \mathrm{g} / \mathrm{l})$

\begin{tabular}{lccc}
\hline $\begin{array}{c}\text { Categoría } \\
\text { trófica }\end{array}$ & $\mathbf{P t}(\boldsymbol{\mu g} / \mathbf{L})$ & $\begin{array}{c}\text { Clor A } \\
\text { Media }\end{array}$ & $\begin{array}{c}\mathbf{m g} / \mathbf{m 3} \\
\text { Maxima }\end{array}$ \\
\hline Ultraoligotrófico & $<4.0$ & $<1.0$ & $<2.5$ \\
\hline Oligotrófico & $<10-35$ & $2,5-8$ & $8,0-25$ \\
\hline Mesotrófico & $10-35$ & $2,5-8$ & $8,0-25$ \\
\hline Eutrófico & $35-100$ & $25-75$ & $25-75$ \\
\hline Hipertrófico & $>100$ & $>75$ & $>75$ \\
\hline
\end{tabular}

Fuente: modificado de OCDE (1982).

Tabla 3b. Estado trófico del humedal El Salitre (Colombia) en tres puntos de muestreo según la concentración de nutrientes en $\mathrm{mg} / \mathrm{L}$ y de clorofila $\mathrm{A}$, equivalente a $\mathrm{mg} / \mathrm{m}^{3}$

\begin{tabular}{ccccccccccc}
\hline \multirow{2}{*}{ Sitio } & \multicolumn{2}{c}{$\begin{array}{c}\text { Estado trófico } \\
\text { basado en el amonio }\end{array}$} & \multicolumn{2}{c}{$\begin{array}{c}\text { Estado trófico } \\
\text { basado en el nitrito }\end{array}$} & \multicolumn{2}{c}{$\begin{array}{c}\text { Estado trófico } \\
\text { basado en el nitrato }\end{array}$} & \multicolumn{2}{c}{$\begin{array}{c}\text { Estado trófico } \\
\text { basado en el fosfato }\end{array}$} & $\begin{array}{c}\text { Estado trófico basado en } \\
\text { la clorofila }\end{array}$ \\
\cline { 2 - 11 } & {$\left[\mathrm{NH}_{4}\right]$} & Categoría & {$\left[\mathrm{NO}_{2}\right]$} & Categoría & {$\left[\mathrm{NO}_{3}\right]$} & Categoría & {$\left[\mathbf{P O}_{4}\right]$} & Categoría & {$[$ [Chl A] } & Categoría \\
\hline Promedio $\mathrm{S}$ & $0,025 \pm 0^{*}$ & $\mathrm{O}$ & $0,0163 \pm 0,006^{*}$ & $\mathrm{O}$ & $0,05 \pm 0^{*}$ & $\mathrm{O}$ & $0,045 \pm 0^{*}$ & $\mathrm{O}$ & $38,64 \pm 13,6^{*}$ & $\mathrm{E}$ \\
\hline Promedio $\mathrm{L}$ & $0,453 \pm 0,005^{*}$ & $\mathrm{M}$ & $0,0035 \pm 0^{*}$ & $\mathrm{O}$ & $0,05 \pm 0^{*}$ & $\mathrm{O}$ & $0,193 \pm 0,065^{*}$ & $\mathrm{E}$ & $45,21 \pm 23,1^{*}$ & $\mathrm{E}$ \\
\hline
\end{tabular}

$\mathrm{S}=$ época seca, $\mathrm{L}=$ época lluviosa, 1, 2, 3= puntos de muestreo

$\mathrm{O}=$ oligotrófico, $\mathrm{M}=$ mesotrófico, $\mathrm{E}=$ eutrófico. La clasificación se basa en los valores de referencia de OCDE (1982) para nitrógeno amoniacal (NH4 +), nitritos (NO2) y nitratos (NO3-), de Dabrowski (2014) para ortofosfatos (PO ${ }_{4}$ ) y de Esteves (1998) para clorofila A $(\mathrm{Chl}$ A). Las concentraciones de los nutrientes se registran en mg L-1 y la de clorofila A en mg m-3. *Desviación estándar de cada variable en cada época de muestreo.

Fuente: modificado de Pulido y Pinilla (2017).
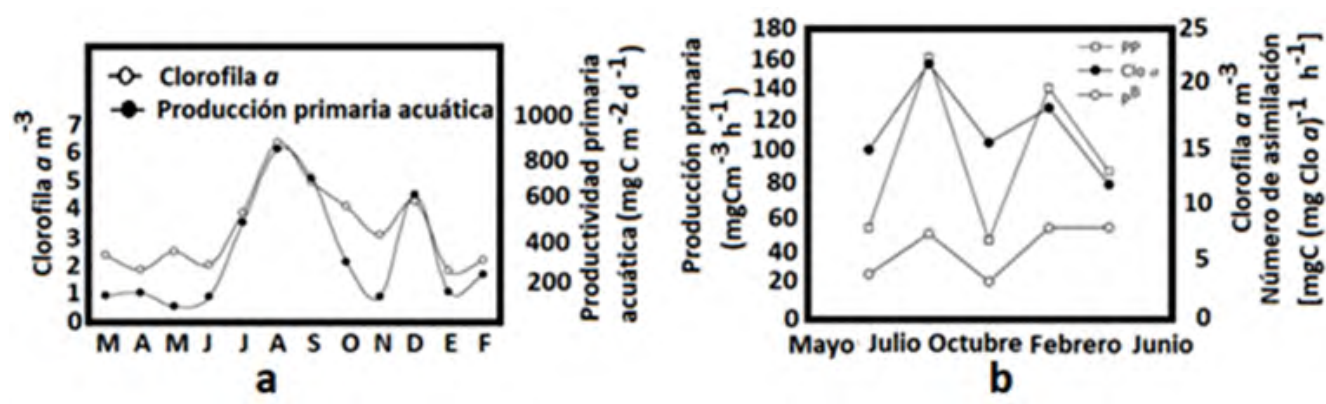

Figura 2. (a) Clorofila a y productividad primaria acuática durante marzo 1998-febrero 1999 en la laguna las Guásimas y (b) producción primaria, clorofila a y número de asimilación calculadas en la laguna Cuyutlán, México, 2004-2005

Fuente: tomadas de Arreola (2003) y Sosa et al. (2013). 


\section{CONCLUSIONES}

Con base en lo expuesto, es recomendable que en cada estudio fisicoquímico del agua en lagunas costeras queden claros cuáles son los objetivos que los autores quieren perseguir: 1) hacer un registro único simple que solo aporta información de una posible condición de impacto puntual generalmente antropogénico, o para asociarlos con la aparición de ciertos organismos; o 2) efectuar un estudio del comportamiento espacio temporal a través de un monitoreo con base en redes de muestreo justificadas en forma ambiental que incluya dinámica física, fluvial, geomorfológica, biológica, actividades humanas acuáticas y terrestres adyacentes, entre otras; pero no referir los resultados como mínimos, máximos y promedios que en muchos casos el intervalo entre el primero y el último puede ser muy amplio y definir una característica errónea o incierta de la fisicoquímica o biología del agua que incluya un grado trófico incierto; además de no ser repetitivo o permanente y variar heterogéneamente tanto en forma espacial como temporal, con parámetros no conservativos distribuidos en parches que no se mantienen constantes, sino que modifican sus concentraciones por diversos factores locales climáticos, hidrológicos, físicos, químicos, entre otros, tanto internos como externos, como se pudo apreciar en las lagunas elegidas del golfo de México y Pacífico mexicano.

\section{REFERENCIAS}

Arreola L., J. A. (2003). Bases de manejo costero: patrones ecológicos en la laguna costera Las Guásimas, territorio Yaqui, México. [Tesis doctoral en Ciencias]. Centro de Investigaciones Biológicas del Noroeste. La Paz, México. Recuperado de http://dspace. cibnor.mx:8080/bitstream/handle/123456789/41/ arreola_j.pdf? sequence $=4 \&$ isAllowed $=y$

Beltrán, V. J. E. (2016). Modelación de la producción primaria fitoplanctónica en el humedal Jaboque, Bogotá D. C. Tecnura, 20(47), 85-95. DOI: http://dx.doi. org/10.14483/udistrital.jour.tecnura.2016.1.a07
Bueno, S. E., Marceleño, S., Nájera, O. y De Haro, R. (2019). Implementación del método de escasez en la determinación de la huella hídrica en la zona costera de San Blas, México. Tecnura, 23(62), 45-54. DOI: https://doi.org/10.14483/22487638.15796

Chapman, D. (1996). Waterqualityassessments: aguide to the use of biota, sediments and water in environmental monitoring. 2a. ed. Londres, Inglaterra: Unesco/ WHO/UNEP. Recuperado de https://apps.who.int/ iris/bitstream/handle/10665/41850/0419216006_ eng.pdf; jsessionid=280BF2988888E7A3FECACF00417B8510? sequence $=1$

Conan, P., Pujo, P. M., Agab, M., Calva, B. L., Chifflet, S., Douillet, P., Dussud, C., Fichez, R., Grenz, C., Gutiérrez, M. F., Origel, M. M., Rodríguez, B. A., Sauret, C., Severin, T., Tedetti, M., Torres, A. R. y Ghiglione, J. F. (2017). Biogeochemical cycling and phyto- and bacterioplankton communities in a large and shallow tropical lagoon (Términos Lagoon, Mexico) under 2009-2010 El Niño Modoki drought conditions. Biogeosciences, 14, 959-975. DOI: https://doi.org/10.5194/bg-14-959-2017

Contreras, E. F. (2010). Ecosistemas costeros mexicanos una actualización. México: Universidad Autónoma Metropolitana-Iztapalapa.

Contreras, E. F. y Warner, B.G. (2004). Ecosystem characteristics and management considerations for coastal. Wetlands in Mexico. Hydrobiologia, 511, 233-245. Recuperado de https://link. springer.com/content/pdf/10.1023\%2FB\%3AHYDR.0000014097.74263.54.pdf

Contreras, E. F., Rivera, G. E. y Segura, A. R. (2005). Nutrientes y productividad primaria fitoplanctónica en una laguna costera tropical intermitente ( $\mathrm{La}$ Mancha, Ver.) del golfo de México. Hidrobiológica, 15(3), 299-310. Recuperado de http://www.scielo. org.mx/pdf/hbio/v15n3/v15n3a6.pdf

Contreras, E. F., Castañeda, O., Torres, R. y Gutiérrez, F. (1996). Nutrientes en 39 lagunas costeras mexicanas. Revista de Biología Tropical, 44(2), 417-425. Recuperado de https://revistas.ucr.ac.cr/index.php/ rbt/article/view/21626/21869

Cony, N. L., Ferrer, N. C. y Cáceres, E. J. (2016). Evolución del estado trófico y estructura de 
fitoplancton de un lago Somero en la región pampeana: laguna Sauce Grande. (Pcia. de Buenos Aires, Argentina). Biología Acuática, 30, 79-91. Recuperado de: https://digital.cic.gba.gob.ar/bitstream/handle/11746/4168/11746_4168.pdf-PDFA. pdf? sequence=1 \&isAllowed $=y$

Dabrowski, J. M. (2014). Applying SWAT to predict ortho-phosphate loads and trophic status in four reservoirs in the upper Olifants catchment, South Africa. Hydrology Earth System Science, 18, 2629-2643, Recuperado de: http://www.hydrol-earth-syst-sci. net/18/2629/2014/hess-18-2629-2014.html

De la Lanza, E. G. y Arenas, F. V. (1978). Naturaleza química de hojas y rizomas de los pastos marinos y su ambiente sedimentario. Revista de Biología Tropical, 26(2), 277-289. Recuperado de https://revistas. ucr.ac.cr/index.php/rbt/article/view/25706/26083

De la Lanza, E. G. y Lozano, M. H. (1999). Comparación fisicoquímica de las lagunas de Alvarado y Términos. Hidrobiológica, 9(1), 15-29. Recuperado de https://hidrobiologica.izt.uam.mx/index.php/ revHidro/article/view/761/351

De la Lanza, E. G., Hernández, P. S. (1999). Informe final de fisicoquímica de la laguna Lagartero, Oax. En: Implementation of a Wave Driven Seawater Pump (SIBEO) to manage Fisheries and Coastal Management in Rural Communities (S. Czitrom, coord.) UNAM/North American Fund for Environmental Cooperation.

De la Lanza, E. G., Hernández, P. S., Penié, R.I. y Gómez, R. J. C. (2006). Calidad del agua de las playas del municipio de Solidaridad Quintana Roo. Revista del Medio Ambiente, Turismo y Sustentabilidad, Universidad del Caribe 2(1), 25-44. Recuperado de https://data.nodc.noaa.gov/coris/library/NOAA/ CRCP/other/other_crcp_publications/revista_medio_ambiente_turismo_sustentabilidad.pdf

De la Lanza, E. G., Alcocer, D. J., Moreno-Ruiz, J. L. y Hernández, P. S. (2008). Análisis químico-biológico para determinar el estatus trófico de la Laguna de Tres Palos Guerrero, México. Hidrobiológica 18(1), 21-30. Recuperado de http://www.scielo. org.mx/pdf/hbio/v18n1/v18n1a3.pdf
De la Lanza-Espino, G., Carbajal-Pérez, J. L., Salinas-Rodríguez, S. A. y Barrios-Ordóñez, J. E. (2012). Medición del caudal ecológico del río Acaponeta, Nayarit; comparando distintos intervalos de tiempo. Investigaciones Geográficas, 78, 62-74. https:// doi.org/10.14350/rig.32470

De la Lanza, E.G., Hernández, P.S. y Carbajal, P.J.L. (2014). Diagnóstico de la calidad del agua de cuatro lagunas costeras de Veracruz. En V.A. Botello, et al. (eds.), Golfo de México: contaminación e impacto ambiental: diagnóstico y tendencias (pp. 817-838). México: UAC, CFE, ICMyL, UNAM, EASAC, CINVESTAV. Recuperado de https://epomex. uacam. $m \times>$ view paginas adjunt

De la Lanza, E. G. y Hernández, P. S. (2017). Physicochemical changes of the water of Alvarado lagoon, Veracruz, Mexico in interrupted periods in middle Century. Journal Aquaculture Marine Biology, 5(4), 00118. DOI: 10.15406/jamb.2017.05.00118 https://doi.org/10.15406/jamb.2017.05.00118

De la Lanza, E. G. y Hernández, P. S. (2018). Water quality in a complex geomorphological lagoon at the Gulf of Mexico, based in recent and compared with information 30 years ago. Journal Aquaculture Marine Biology, 7(5), 253-256. DOI: https:// medcraveonline.com/JAMB/JAMB-0700216. pdf.10.15406/jamb.2018.07.00216

De la Lanza, E. G. y Gutiérrez, M. F. (2019). Número y diversidad de sistemas costeros mexicanos, su fisicoquímica, comportamiento e impactos antropogénicos. En A. V. Botello, F.S. Villanueva y J. Gutiérrez (eds.). Las costas mexicanas. Contaminación, impacto ambiental, vulnerabilidad y cambio climático (pp. 1-24): México: UNAM, UAC. DOI: 10.26359.376639.

Esteves F.A. (1998). Fundamentos de limnología. 2a. ed. Brasil: Interciência.

Fichez, R., Linares, C., Chifflet, S., Conan, P., Contreras, R., Esparza, A., Denis, L., Douillet, P. L., Grenz, C., Ghiglione, J. F., Gutiérrez, M. F., Origel, M. M., Muñoz, C. A., Pujo P. M. y Zavala H. J. (2019). Spatiotemporal variability in Terminos Lagoon (Mexico) Waters during the 2009-2010 drought 
reveals upcoming trophic status shift in response to climate change. Regional Environmental Change, 19, 1787-1799. DOI: https://doi.org/10.1007/ s10113-019-01519-2

Florencio, B. F. J., Huertas, R. M. J. y López, M. L. (2019). ¿Pueden las cianobacterias crecer igual en luz y oscuridad, cerrando el Ciclo de Krebs? España: Universidad de Sevilla. Recuperado de https://investigacion.us.es/sisius/sis_proyecto. php?idproy=27079

Gaxiola-Castro, G., Cepeda-Morales, J., Nájera-Martínez, S., Espinosa-Carreón, T. L., De la Cruz-Orozco, M. E., Sosa-Avalos, R., Aguirre-Hernández, E. y Cantú-Ontiveros, J. P. (1997). Biomasa y producción del fitoplancton. Dinámica del ecosistema pelágico frente a Baja California, 2007, 59-85. Recuperado de http://www2.inecc.gob.mx/publicaciones2/libros/642/biomasa.pdf

Gómez, O. R., De la Lanza, E. G., Tovilla, H. C., Barba, M. E., Valle, M. J., Castañeda, L. O. y Ramos, S. E. (2017). Cambios ambientales y tróficos a través de un análisis a largo plazo del sistema Lagunar Chantuto-Panzacola, Chiapas, México. Ciencias Marinas y Costeras, 9(2), 75-100. DOI: https://doi. org/10.15359/revmar.9-2.4

González, F., Zoppi de Roa, E. y Montiel, E. (2006). Productividad primaria del fitoplancton en la bahía de Mochima, Venezuela. Investigaciones Marinas, 34(2), 37-45. DOI: http://dx.doi.org/10.4067/ S0717-71782006000200004

Gutiérrez, M. F. J. y De la Lanza, E. G. (2019). Physicochemical characterization of Mexican Coastal lagoons, current status, and future environmental scenarios. En A. L. Ibáñez (ed.), Mexican aquatic environments. A general view from hydrobiology to fisheries. (pp 77-92). México: Springer. Recuperado de https:// www.springer.com/gp/book/9783030111250_https://doi.org/10.1007/978-3-030-11126-7_3

Hernández, Á. I. y Gómez, G. A. (2014). Patrones de abundancia y composición del zooplancton costero a varias escalas temporales en un ciclo de surgencia estacional en la isla de Margarita, Venezuela. Interciencia 39(2), 122-128. Recuperado de https:// www.redalyc.org/pdf/339/33930068008.pdf
Land-Ocean Interaction in the Coastal Zone (LOICZ) Project of the IGBP (1998). Towards integrated modelling and analysis in coastal zones: principles and practices. International Geosphere Biosphere Programme University of Maryland Center for Environmental Science. Países Bajos. Recuperado de https://s3-eu-west-2.amazonaws.com/futureearthcoasts/wp-content/uploads/2018/05/30150925/ LOICZ-RS11.pdf

Lara, L. J. R. y Álvarez, B. S. (1975). Ciclo anual de clorofilas y producción orgánica primaria en Bahía San Quintín, B.C. Ciencias Marinas, 2(1), 77-97. Recuperado de https://cicese.repositorioinstitucional.mx/jspui/bitstream/1007/1991/1/116901.pdf https://doi.org/10.7773/cm.v2i1.266

Lara, L. J. R. y Bazán, G. C. (2005). Distribución de la clorofila y producción primaria por clases de tamaño en la costa del Pacífico mexicano. Ciencias Marinas, 31(1A), 11-21. Recuperado de https://www. redalyc.org/pdf/480/48031102.pdf__ https://doi. org/10.7773/cm.v31i11.82

Lara, L. J. R., Arreola, L. J. A., Calderón, A. L. E., Camacho, I. V. F., De la Lanza, E. G., Escofet, G. A., Espejel, C. M. I., Guzmán, A. M., Ladah, L. B., López, H. M., Meling, L. E. A., Moreno, C. B. P., Reyes, B. H., Ríos, J. E. y Zertuche, G. J. A. (2008). Los ecosistemas costeros, insulares y epicontinentales. En Capital natural de México. Vol. I Conocimiento actual de la biodiversidad (pp. 109-134). México: Conabio. Recuperado de: https://www.biodiversidad.gob.mx/v_ingles/country/pdf/CapNatMex/ Vol\%201/104_Losecosistemascos.pdf

Mann, K. y Lazier, J. (1991). Dynamics of marine ecosystems. Boston, EE. UU.: Blackwell Scientific Publications. Recuperado de http://www. marineornithology.org/PDF/35_2/35_2_155.pdf

Marín, V. H. y Olivares, G. R. (1999). Estacionalidad de la productividad primaria en Bahía Mejillones del Sur (Chile): una aproximación proceso-funcional. Revista Chilena de Historia Natural, 72, 629641. Recuperado de http://rchn.biologiachile.cl/ pdfs/1999/4/Marin_\%26_Olivares_1999.pdf

Montoya, Y. y Aguirre, N. (2010). Dinámica de la producción primaria fitoplanctónica en un lago 
tropical (ciénaga Escobillitas) a lo largo del pulso de inundación. Revista Facultad de Ingeniería Universidad de Antioquia, 55, 76-89. Recuperado de http://www.scielo.org.co/pdf/rfiua/n55/n55a08.pdf

Organización para la Cooperación y el Desarrollo Económico (OCDE) (1982). The OCDE List of Social Indicators. París.

Pérez, C. A. G. y Rodríguez, A. (2008). Índice fisicoquímico de la calidad de agua para el manejo de lagunas tropicales de inundación. Revista Biología Tropical, 56(4), 1905-1918. Recuperado de https:// www.scielo.sa.cr/pdf/rbt/v56n4/art26v56n4.pdf_https://doi.org/10.15517/rbt.v56i4.5769

Pirela, O. E., Troccoli, L. y Hernández, A. I. (2008). Hidrografía y cambios en la comunidad del microfitoplancton de la bahía de Charagato, isla de Cubagua, Venezuela. Boletín del Instituto de Oceanografía, 47(1), 3-16. Recuperado de https://www. academia.edu/22100067/Hidrograf\%C3\%ADa_y_ cambios_en_la_comunidad_del_microfitoplancton_de_la_Bah\%C3\%ADa_de_Charagato_Isla_de_ Cubagua_Venezuela

Pulido, L. P. C. y Pinilla, A. G. A. (2017). Evaluación del estado trófico de El Salitre, último humedal urbano de referencia en Bogotá. Revista Académica Colombiana de Ciencias Exactas, Físicas y Naturales, 41(158), 41-50. DOI: http://dx.doi.org/10.18257/ raccefyn. 411

Quiroz, C. N. N. (2014). Variabilidad de la productividad fitoplanctónica en el sistema lagunar Navachiste. [Tesis de maestría]. Instituto Politécnico Nacional. Centro Intedisciplinario de Investigación para el Desarrollo Integral Regional Unidad Sinaloa, México. Recuperado de https://tesis.ipn.mx/ bitstream/handle/123456789/13164/Quiroz\%20 del\%20Campo $\% 20$ Nallely $\% 20$ Nohem $\%$ C3\%AC. pdf? sequence $=1$ \&isAllowed $=y$

Robayo, M. L. X. y Rodríguez, L. C. A. (2015). Evaluación de la productividad primaria fitoplanctónica a partir de la medición de oxígeno disuelto en tres lagunas del sistema lacustre de Chingaza. [Tesis doctoral]. Universidad Santo Tomás,
Ingeniería Ambiental. Bogotá, Colombia. Recuperado de https://repository.usta.edu.co/bitstream/ handle/11634/622/Evaluacion\%20de\%20la\%20 productividad $\% 20$ primaria $\% 20$ fitoplanctonica\%20a\%20partir\%20de\%20la\%20medicion $\% 20$ de $\% 20$ oxigeno $\% 20$ disuelto $\% 20$ en $\% 20$ tres $\% 20$ lagunas $\% 20$ del\%20sistema $\% 20$ la $\% 20$ cuestre $\% 20$ de\%20Chingaza. pdf? sequence $=1$ \&isAllowed $=y$

Ryther, J. H. y Yentsch, C. S. (1957). The estimation of phytoplankton production in the ocean from chlorophyll and light data. Limnology and Oceanography 2(3), 281-286. DOI: https://doi.org/10.1002/ Ino.1957.2.3.0281

Smith, S. V., Ibarra, O. S., Boudreau, P.R. y Camacho, I. V. F. (1997). Comparisons of carbon, nitrogen and phosphorus fluxes in mexican coastal lagoon. LOICS Reports and Studies, 10. Texel, Países Bajos. DOI: 10.13140 / RG.2.1.5134.5126

Sosa, A. R., Millán, N. R. y Santamaría, A. E. (1997). Productividad primaria del fitoplancton estimada con los métodos de oxígeno y carbono catorce en una estación del estero de punta banda, México. Ciencias Marinas, 23(3), 36l-375. Recuperado de http://www.redalyc.org/articulo.oa?id=48023306

Sosa, A. R., Gaxiola, C. G., Olivos, O. A. e Iñiguez, L. S. (2013). Nutrientes inorgánicos y producción del fitoplancton en una laguna costera subtropical de México. Revista de Biología Marina y Oceanografía, 48(1), 143-154. DOI: https://doi.org/10.4067/ S0718-19572013000100012

Thienemann A. (1931). Tropische Seen und Seetypen. Archiv für Hydrobiologie, Supplement, 9, 205-231. Recuperado de https://www.sciencedirect.com/ science/article/pii/S0380133081720446

Wetzel, G. R. (1975). Limnology. Lake and river ecosystem. Cambridge, Massachusetts: Academic Press, Elsevier.

Willmer, P., Stone, G. y Johnston, I. (2005). Environmental physiology of animals. 2a. ed. Reino Unido: Blackwell Publishing Company. Recuperado de https://jajo66.files.wordpress.com/2010/10/environmental-physiology-of-animals.pdf

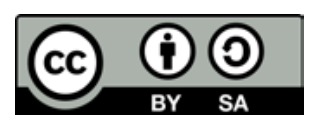

Tecnura • p-ISSN: 0123-921X • e-ISSN: 2248-7638 • Vol. 24 No. 65 • Julio - Septiembre de 2020 • pp. 85-101 [ 101 ] 